Article

\title{
Impacts of Urban Form on Thermal Environment Near the Surface Region at Pedestrian Height: A Case Study Based on High-Density Built-Up Areas of Nanjing City in China
}

\author{
Junyan Yang, Beixiang Shi $₫$, Geyang Xia, Qin Xue and Shi-Jie Cao *® \\ School of Architecture, Southeast University, Nanjing 210096, China; yangjy_seu@163.com (J.Y.); \\ shi_bx_seu@seu.edu.cn (B.S.); xia_geyang@163.com (G.X.); xue_qin@seu.edu.cn (Q.X.) \\ * Correspondence: shijie_cao@seu.edu.cn or shijie.cao09@gmail.com
}

Received: 13 January 2020; Accepted: 23 February 2020; Published: 26 February 2020

check for updates

\begin{abstract}
The continuous worsening of urban thermal environments poses a severe threat to human health and is among the main problems associated with urban climate change and sustainable development. This issue is particularly severe in high-density built-up areas. Existing studies on the thermal environments (temperature data extracted from satellite remote sensing images) are mainly focused on urban canopy areas (airspace below the average height of trees or buildings) rather than the near surface region (at pedestrian height). However, the main outdoor activity space of urban residents is the area near surface region. Hence, this study aims to investigate the influence of urban form (i.e., building density, height, and openness) on thermal environment near the surface region. The high-density built-up areas of a typical megacity (i.e., Nanjing) in China were selected, and the thermal environments of 26 typical blocks were simulated using ENVI-met software. Temperature field measurements were carried out for simulation validation. On this basis, a classified and comparative study was conducted by selecting the key spatial form elements that affect thermal environments. The results showed that in actual high-density built-up areas, single urban form parameter does not determine the thermal environments near the urban surface but mainly affected by the use (function) of space. For this study, the overall thermal environment of a street block is optimal when the building density is between $40 \%$ and $50 \%$ and the average building height is between 8 and 17 stories. Nonetheless, the urban form can be improved to optimize the overall effects on building functions and thermal environments. Furthermore, function-specific urban form optimization strategies were proposed to optimize thermal environments according to specific functional needs.
\end{abstract}

Keywords: near surface space; thermal environment; urban form; high-density built-up area; ENVI-met modeling

\section{Introduction}

Urbanization not only provides a high quality of urban life, but also causes various environmental problems (e.g., climate change [1,2]), which have received increasing attention in society [3]. Global climate change has affected human life severely, producing numerous problems, such as health hazards [4,5], population migration [6,7], and even threats to life. The situation is particularly severe in Asian cities with high-density distributions of people and buildings. In India, extreme heat waves killed 1300 urban residents in 2010 and 1500 people in 2013 [8]. Hence, the thermal-affected environment problem in cities is an important issue, which is mainly related to urban climate change and sustainable development. High density is considered to be an inevitable trend in urban construction and plays 
an important role in improving the quality of human life, promoting the healthy development of cities [9], improving urban traffic, and reducing energy consumption [10]. However, high density also aggravates the urban heat island effect and poses a threat to human health. Mitigation of heat wave along with urban heat island effect, associated with high-density built-up areas in cities are important topics of research and is the focus of this study.

Chen et al. [11] noted that over the past decades, urban construction has changed the urban form on the surface of the earth, as well as the urban microclimate (e.g., air temperature and surface temperature), thereby affecting the heat conduction and convection of near surface air. In built-up areas, the urban heat island effect is primarily influenced by the vertical spatial layout (i.e., building height), building density, and amount of green open space [12-15]. Among the urban microclimate elements, solar radiation and ventilation (through atmospheric wind conditions [16]) are significantly affected by the vertical urban form. High-rise buildings obstruct sunshine and wind, therefore, heat and hazardous substances cannot evaporate smoothly, causing the increase of air temperature [17,18]. In terms of building density, a compact building layout obstructs the incoming wind, reducing the wind speed and affecting the urban thermal environment [19]. The surface material of green open space disturbs solar radiation and its transpiration, thereby increasing the air humidity, promoting air circulation, and reducing heat-island circulation inside high-density built-up areas [20].

In high-density built-up areas, the thermal environment problem is particularly severe. In these areas, the construction scale, land coverage, and degree of population agglomeration are all high, so urban morphology is mainly characterized by small street blocks, high building densities, small building intervals, and ground surfaces dominated by hard squares $[3,15]$. Correspondingly, the amount of urban open space is very limited, and it is difficult to achieve large-scale green land and high plant coverage, and therefore the traditional method of counteracting the heat island effect can hardly produce ideal results [21]. The variation of building height affects the sunshine and shadows inside street blocks, changing the urban near surface temperature [22]; an extremely high building density slows down the near surface airflows, causing poor ventilation [19]. Consequently, not only air circulation and pollutant dispersion, especially in the near surface region [10,18] are obstructed [23], but also the urban climate and heat island effect are affected [24,25], which eventually leads to the loss of self-regulation ability of an urban ecosystem.

However, the most existing studies on thermal environments (reflecting the characteristics of urban canopy layer), are based on air temperature data acquired via fixed-point meteorological observations and satellite remote sensing imaging by automatic meteorological stations in the professional observational networks operated by weather bureaus [25-29]. Such average temperature data can only reflect the conditions in the urban canopy layer and differ significantly from the urban near surface air temperature perceived by humans (as shown in Figure 1). However, the near surface space is the main area in which urban residents perform outdoor activities and is affected by the thermal environment more significantly [30]. Therefore, strategies for mitigating the urban heat island effect and measures for adjusting the urban air temperature based on the data measured by urban meteorological stations cannot be utilized to optimize urban near surface thermal environments directly. The thermal environment problem (urban heat island effect, urban heat wave, and thermal comfortable problem) in the near surface region is yet to be studied and addressed effectively. 


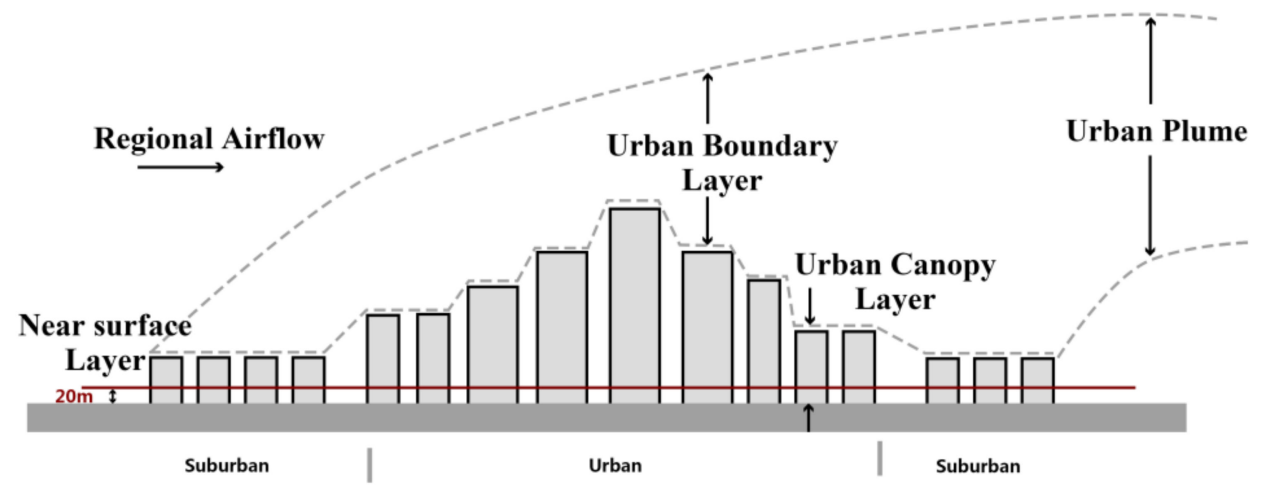

Figure 1. Difference between urban canopy layer and near surface layer.

Some scholars contend that the negative effects of urban thermal environments can be reduced through intervention by manipulating the elements of urban morphology [31,32]. However, specific methods or strategies for near surface space optimization are rarely proposed. Therefore, this study mainly focused on optimizing thermal environments in the near surface region from the perspectives of urban form interactions. The effects of the near surface urban form on the thermal environment were investigated based on simulations of the thermal environments and urban form in typical high-density built-up areas, and a means of optimizing thermal environments by optimizing the urban form in high-density built-up areas was further discussed. However, the thermal environment in the near surface is affected by diverse factors, including solar radiation, thermal discharge of air conditioners, light reflex, and heat dissipation of motor vehicles, which were not addressed specifically in this study. Instead, thermal environments were simulated based on actually measured temperature data, and the relationship between the high-density urban form and thermal environment was maintained as the focus. Furthermore, it was asserted that actually measured data can directly reflect the effects of various factors but do not affect the relationship between the urban form and thermal environment.

\section{Measurement and Simulation Methods of Thermal Environments}

\subsection{Study Framework}

XCZ (namely, Xijiekou Centralized Zone) was selected in Nanjing, a typical high-density megacity of China. The thermal environment of XCZ was measured to obtain thermal environment data of an actual urban space; then, its thermal environment was simulated using ENVI-met software, and the simulation results were verified. On this basis, typical high-density street blocks were selected from XCZ. The relationship between the urban form and thermal environment was studied in three respects (i.e., building density, building height, and degree of openness), and a highly anticipated urban form to optimize the thermal environments of high-density built-up areas were proposed (as shown in Figure 2). 


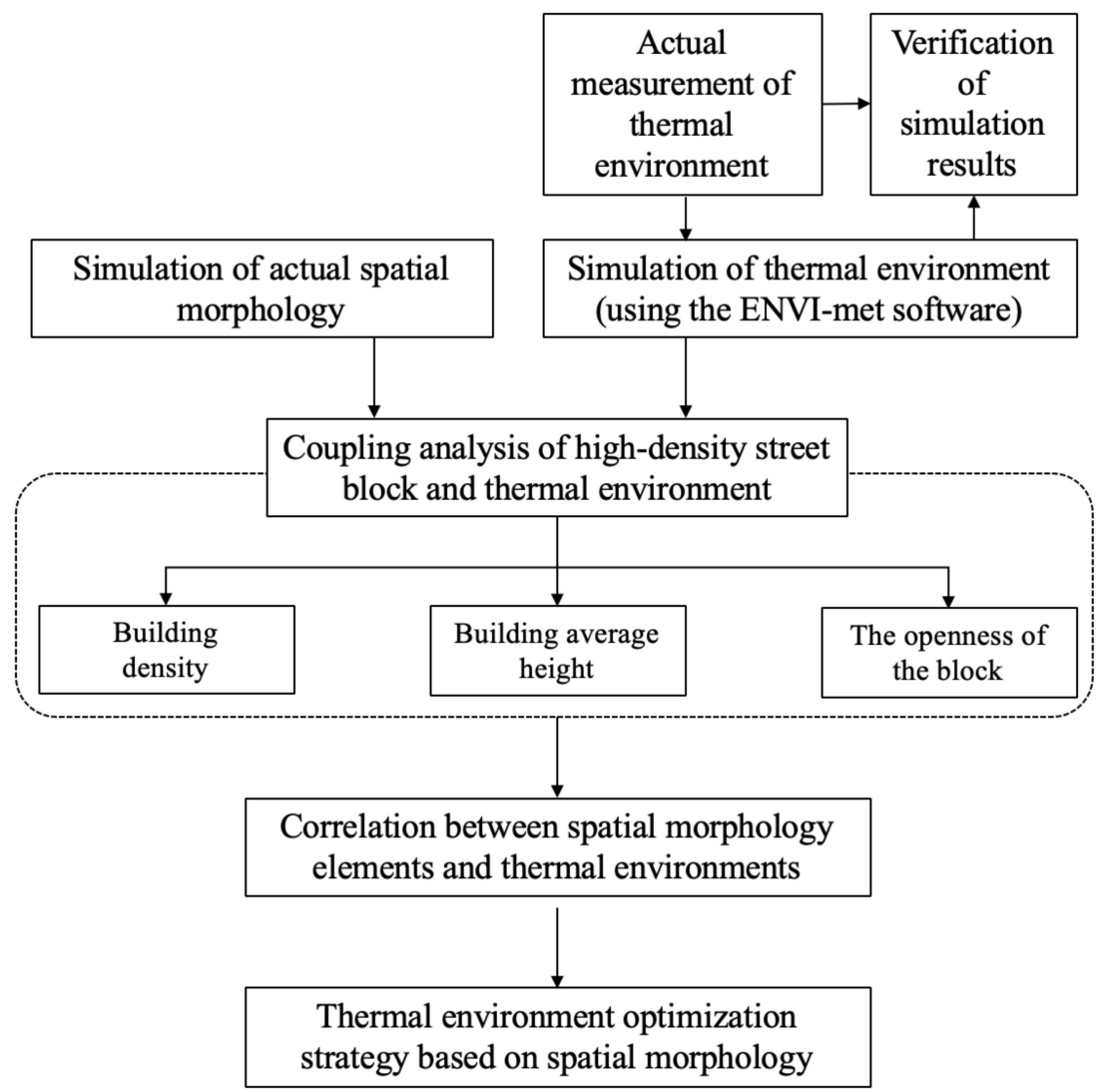

Figure 2. Research framework.

\subsection{Study Case}

Located in the middle to lower reaches of the Yangtze River (shown in Figure 3), Nanjing has a population of approximately 8.4362 million and is a typical megacity. Nanjing is dominated by the northern subtropical monsoon climate with a hot summer and cold winter. According to the statistical data from the China Meteorological Administration, the average annual temperature in Nanjing is $15.4^{\circ} \mathrm{C}$, its annual extreme maximum temperature is $39.7^{\circ} \mathrm{C}$, and its annual extreme minimum temperature is $-13.1{ }^{\circ} \mathrm{C}$. The average relative humidity reached $75 \%$. The prevailing winds in summer are easterly and southeasterly, with an average wind speed of $2 \mathrm{~m} / \mathrm{s} \sim 3 \mathrm{~m} / \mathrm{s}$. XCZ, the primary center of Nanjing, is characterized by busy road traffic and a dense distribution of high-rise buildings, being a typical high-density built-up area (as shown in Figure 4). According to a related study, XCZ covers an area of $5.66 \mathrm{~km}^{2}$ with a floor-area ratio of 2.3 [33]. Although XCZ is a high-density built-up area, not all street blocks are of high density. The maximum building density of all blocks in XCZ is $60 \%$, while the minimum building density is merely $20 \%$. A building density of $30 \%$ was used as the threshold level for a high-density street block. Specifically, a street block with a building density of at least $30 \%$ can be referred to as a high-density street block [16,34]. Hence, the relationship between the urban form and thermal environment was addressed, focusing on the street blocks of XCZ with building densities of at least $30 \%$. 


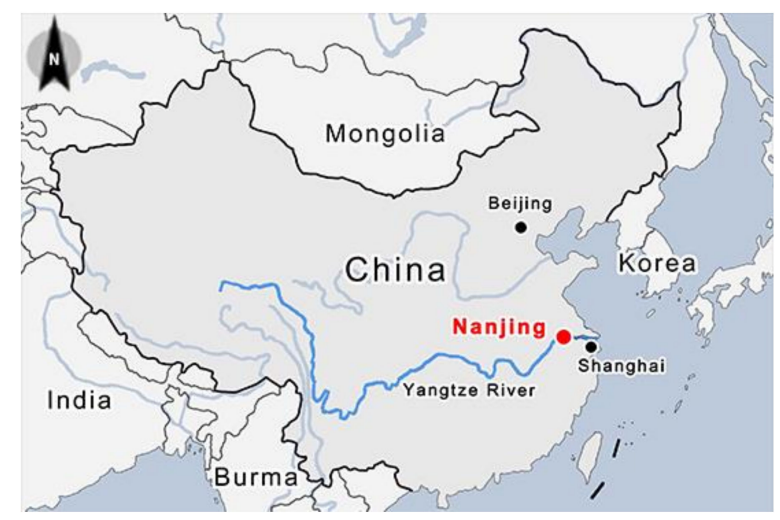

Figure 3. Location of Nanjing.

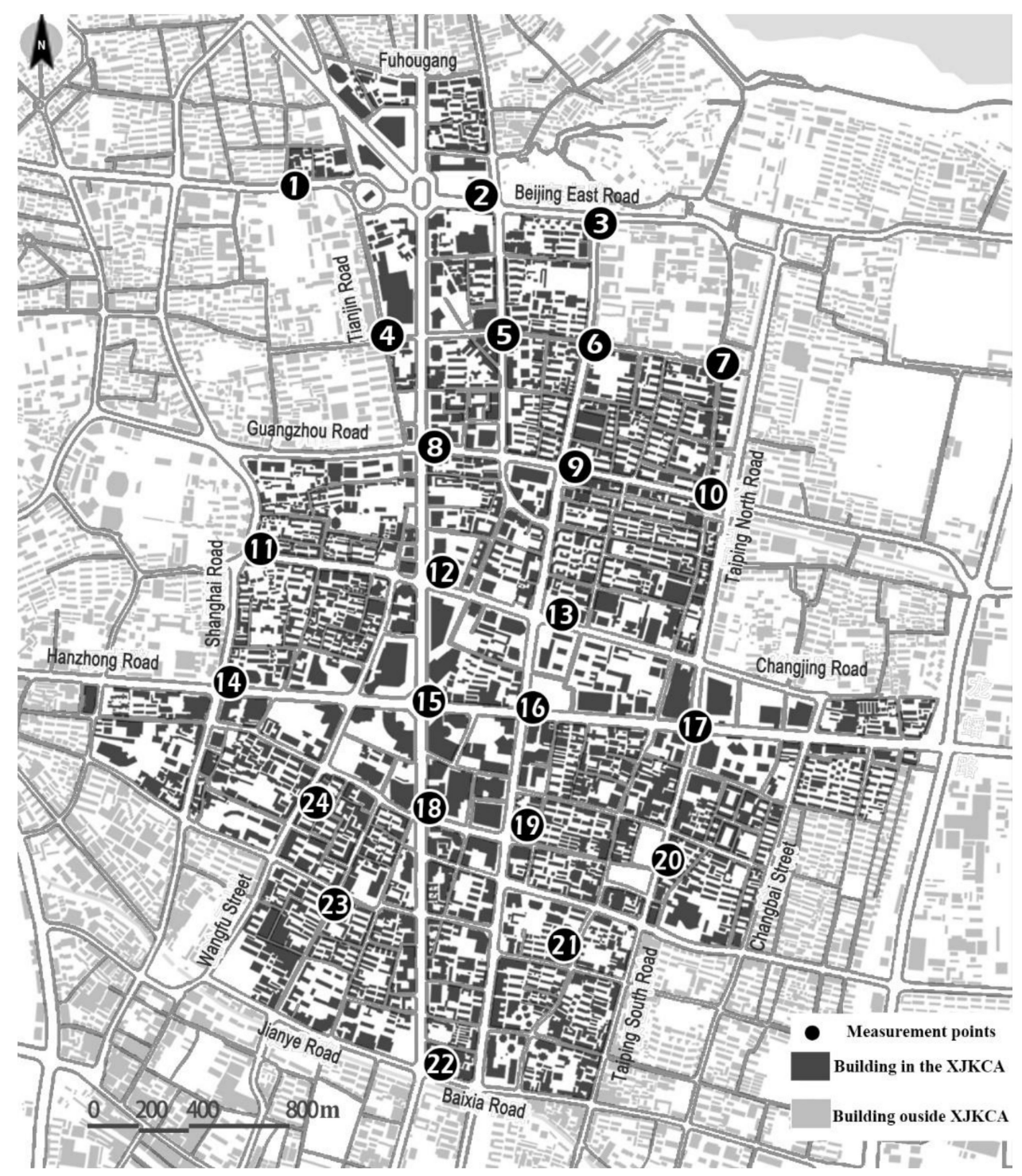

(a)

Figure 4. Cont. 


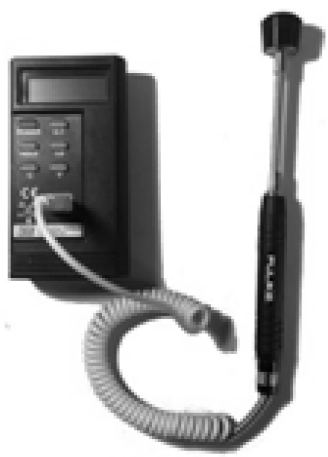

(b)

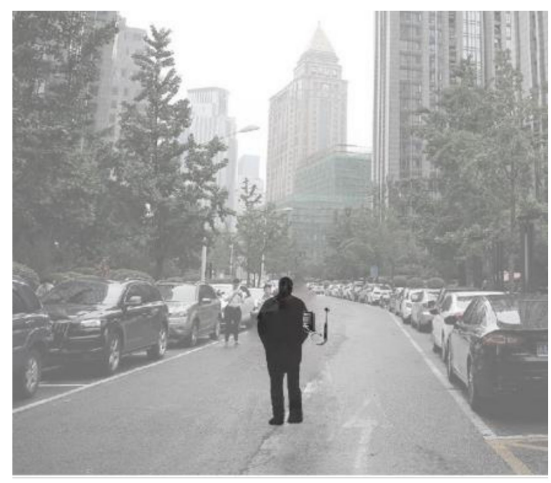

(c)

Figure 4. (a) Range and form of Xijiekou Centralized Zone (XCZ) and distribution of measurement points (with numbered-round circle); (b) TES-1310 portable electronic thermodetectors; (c) scene of measurement.

\subsection{Measurement, Simulation, and Verification of Near Surface Thermal Environments}

The date of actual measurement was a Friday, 29 June 2018, when it was sunny and cloudless, the average temperature was $28.5^{\circ} \mathrm{C}$, the average surface temperature was $29.9^{\circ} \mathrm{C}$, and the average relative humidity was $65.2 \%$. There were 24 measurement points in total (as shown in Figure 5). The measurement period was from 8:00 to 17:00, and measurement was performed every hour. The main measurement devices included TES-1310 portable electronic thermodetectors and portable electronic thermohygrometers. For each TES-1310 portable electronic thermodetector, the inductors were K-type thermocouples; when the measured temperature ranged from -50 to $199.9^{\circ} \mathrm{C}$, the recognition rate was $0.1^{\circ} \mathrm{C}$ and the accuracy rate was $0.2 \% \mathrm{rdg}+1^{\circ} \mathrm{C}$. Two probes were used to measure the air temperature at the pedestrian height and the surface temperature at each measurement point. Portable electronic thermohygrometers were used to measure the relative air humidity at the pedestrian height $(1.5 \mathrm{~m}$ above the ground) at each measurement point. Figure 5 lists the actual measurement results.

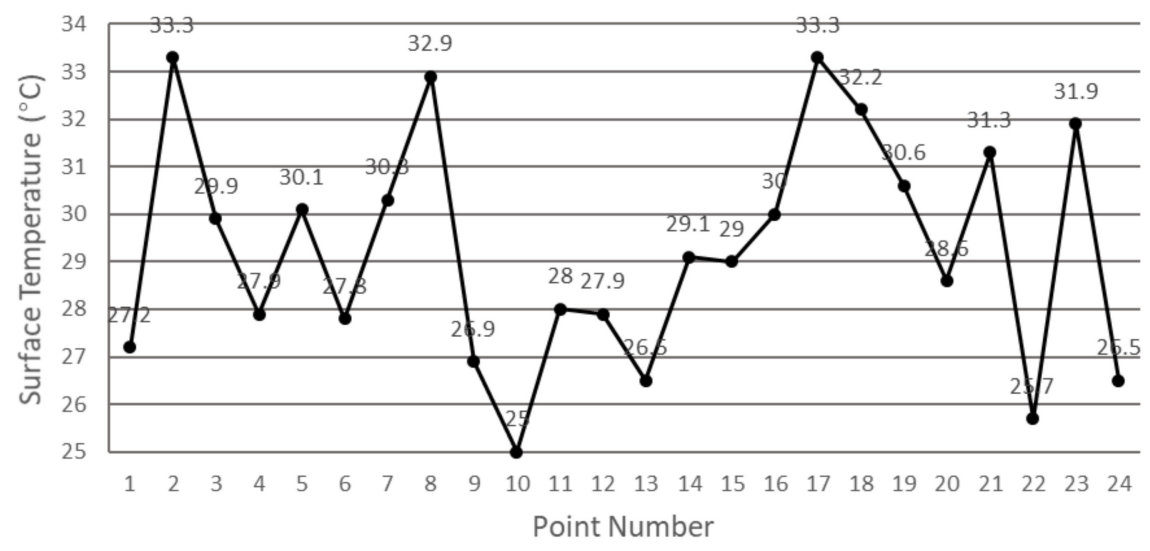

(a) surface temperature $\left({ }^{\circ} \mathrm{C}\right)$ at different locations.

Figure 5. Cont. 


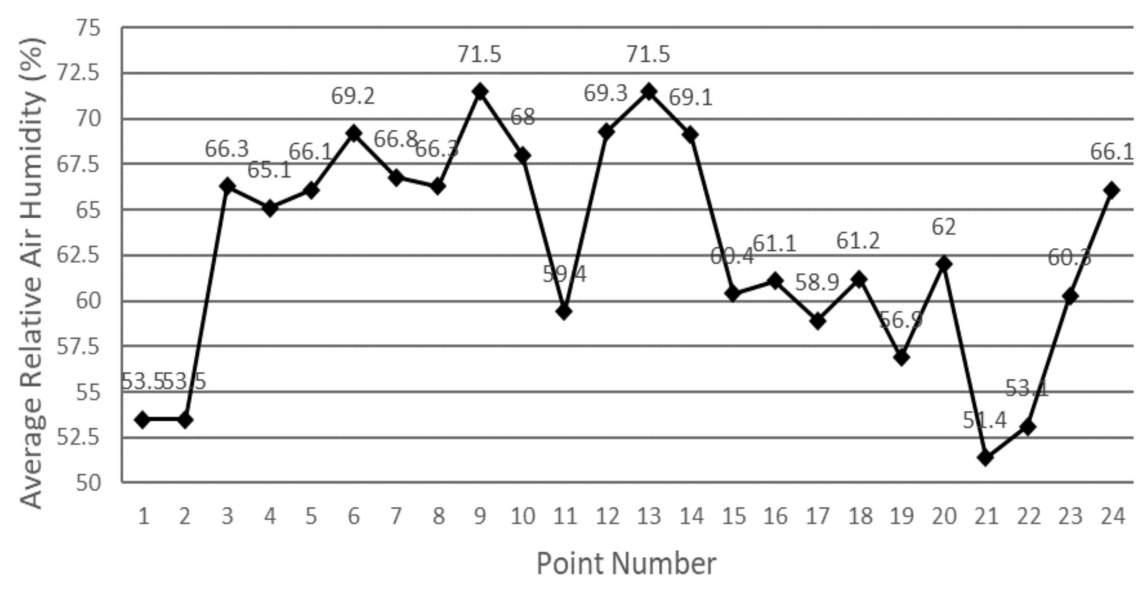

(b) the averaging relative air humidity (\%) at different locations.

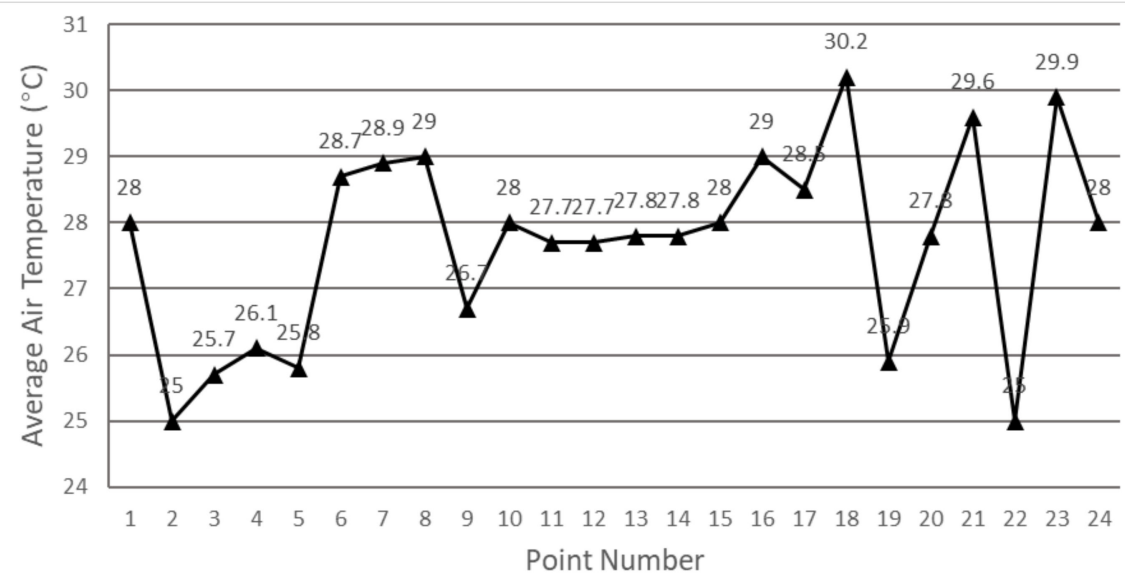

(c) the averaging temperature (at pedestrian height) $\left({ }^{\circ} \mathrm{C}\right)$ at different locations.

Figure 5. Measured data of thermal environment at different locations (shown in Figure 4) of XCZ.

The measured data of thermal environment for simulations setup are described in Table 1. Among them, the simulated climatic conditions included the prevailing wind direction (southeast by south) and average prevailing wind speed $(2.8 \mathrm{~m} / \mathrm{s})$ in summer in Nanjing (NMB, 2018). The near surface thermal environment of $\mathrm{XCZ}$ was simulated using ENVI-met software, and the simulation results were verified. Developed by Michael Bruse (University of Mainz, Germany), ENVI-met is a three-dimensional dynamic microclimate model. In the field of urban climatology, ENVI-met has been widely used to simulate urban outdoor environments [35], which can be used to calculate the interaction between a solid surface and air for a simulated urban environment. It can provide a spatial accuracy of 0.5 to $10 \mathrm{~m}$ and a temporal accuracy of $10 \mathrm{~s}$ for the typical urban grid model. ENVI-met can be utilized to calculate the dynamic microclimate within a period of 24 to $48 \mathrm{~h}$. According to the selected sample spots with block label (ref. Table 2 and Figure 6), a series of 24 typical urban grid models were established, with the size of $1 \times 1 \times 3 \mathrm{~m}$ for each model and the mesh grid of $250 \times 250 \times 30$. 
Table 1. Parameters setup for simulations with ENVI-met.

\begin{tabular}{cc}
\hline Simulation Parameters & Input Parameter Value \\
\hline Start simulation at day (DD.MM.YYY) & $=29.06 .2018$ \\
\hline Start simulation at time (HH:MM:SS) & $=06: 00: 00$ \\
\hline Total simulation time (hours) & $=24$ \\
\hline Save model state frequency (min) & $=60$ \\
\hline Wind speed in 10 m ab. ground (m/s) & $=2.8$ \\
\hline Wind direction (0:N..90:E..180:S..270:W..) & $=145$ \\
\hline Roughness length z0 at reference point & $=30.1$ \\
\hline Initial temperature atmosphere (K) & $=8$ \\
\hline Specific humidity in 2500 m (g water/kg air) & $=62$ \\
\hline Relative humidity in 2 m $(\%)$ &
\end{tabular}

Table 2. Selected spots for simulations.

\begin{tabular}{cccc}
\hline $\begin{array}{c}\text { Spot } \\
\text { Number }\end{array}$ & Plot Attribution & $\begin{array}{c}\text { Spot } \\
\text { Number }\end{array}$ & Plot Attribution \\
\hline 03 & Financial and business & 36 & Residential \\
\hline 04 & Financial and business & 40 & Commercial \\
\hline 07 & Residential & 42 & Residential \\
\hline 08 & Residential & 46 & Financial and business \\
\hline 10 & Commercial & 51 & Residential \\
\hline 13 & Residential & 53 & Commercial \\
\hline 14 & Residential & 57 & Financial and business \\
\hline 18 & Residential & 65 & Residential \\
\hline 19 & Residential & 66 & Residential \\
\hline 20 & Financial and business & 67 & Financial and business \\
\hline 22 & Residential & 71 & Residential \\
\hline 35 & Residential & 76 & Financial and business \\
\hline
\end{tabular}

To further ensure the reliability of the experiment, the simulation results were compared with monitored data. In a simulated thermal environment, there was a certain bias between the actually measured and simulated temperatures. Using the percentage error calculation equation (Equation (1)), the percentage errors of the thermal environment simulation experiment were determined to be as follows: The minimum percentage error of the temperature was $1.05 \%$, the maximum percentage error of the temperature was $17.15 \%$, and the average statistical error of the measurement points was $3.75 \%$ (as shown in Figure 7). The overall value is within the acceptable error range of the experiment, indicating that the simulation results are relatively reliable [36].

$$
\delta=\frac{|a-b|}{a} \times 100 \%
$$

where $a$ denotes a measured value and $b$ denotes a simulated value. 


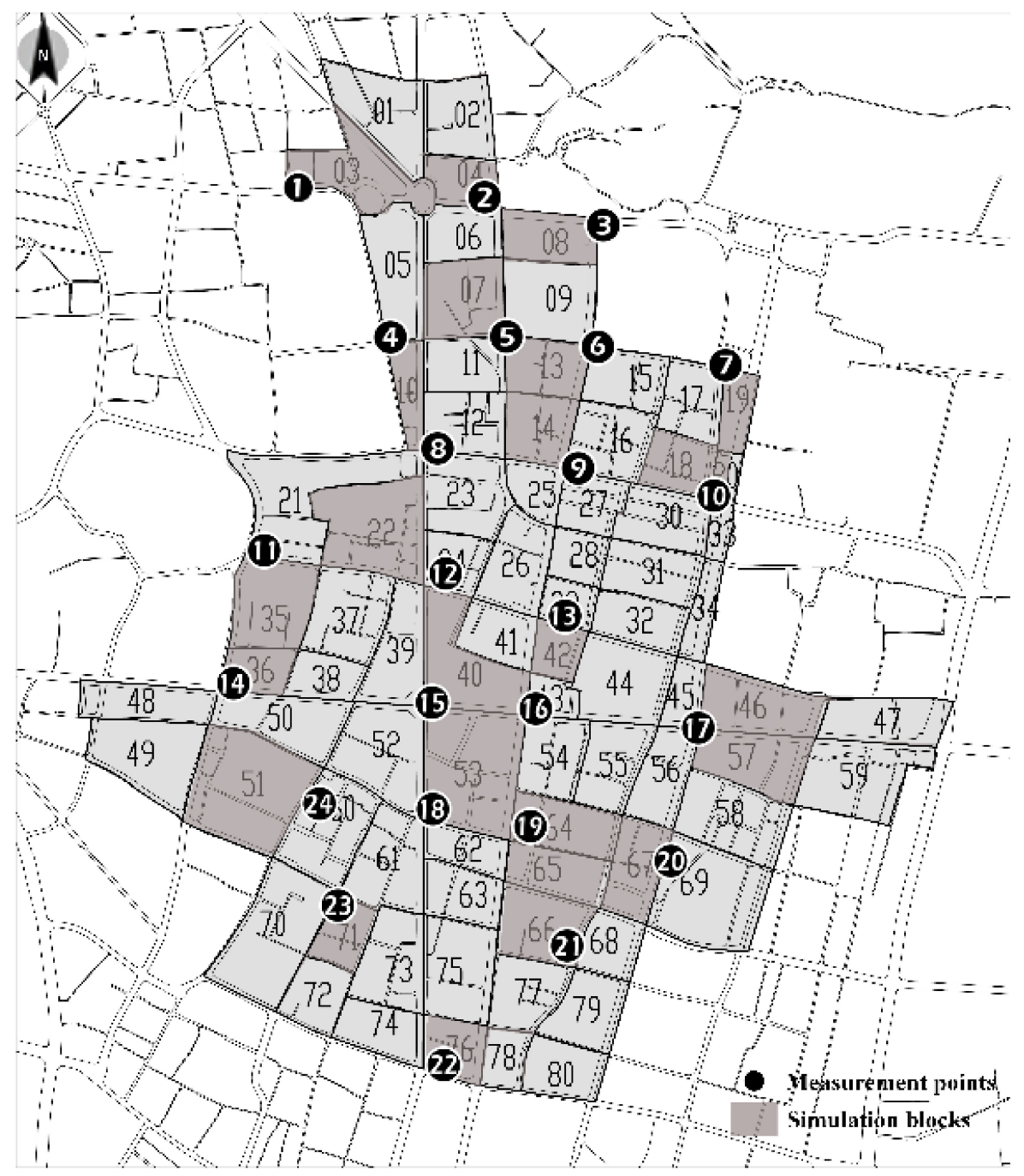

Figure 6. Division of XCZ with block labels indicated.

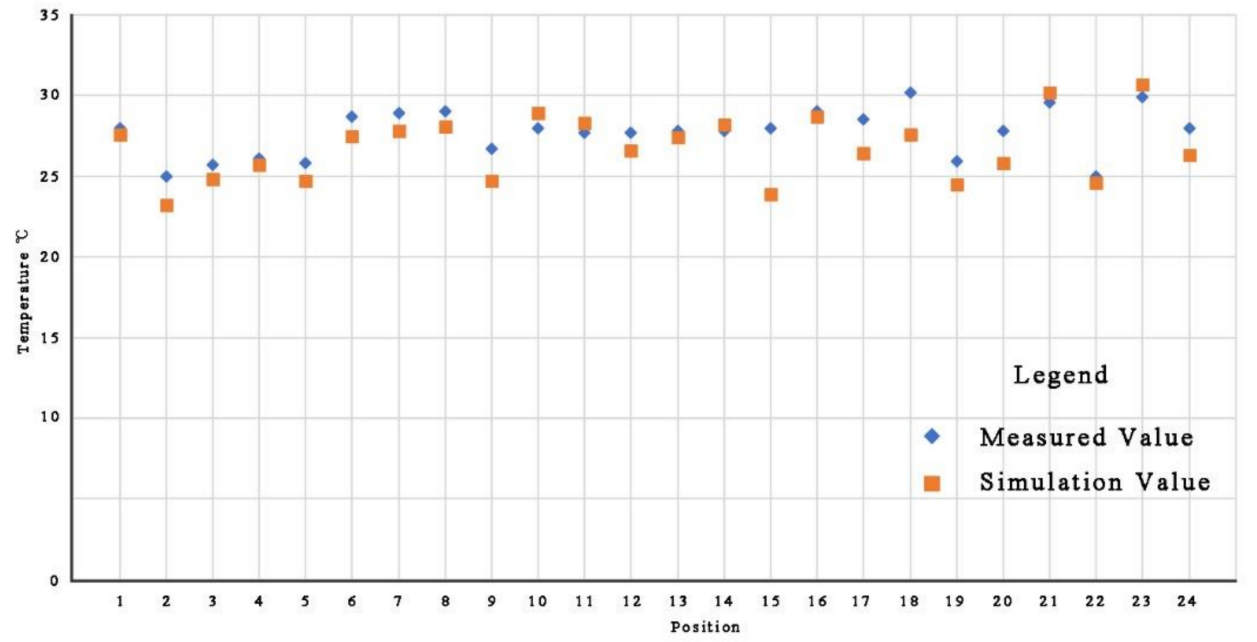

Figure 7. Measured thermal environment (i.e., temperature at each measured point) of XCZ versus simulated data. 


\section{Simulation of Near Surface Thermal Environments of Typical Street Blocks}

\subsection{Building Density Versus Thermal Environment in Near Surface Space of XZC}

The building density reflects not only the size of lot construction but also the density of building in street blocks. It is one of the indexes to evaluate the urban form of street blocks [19]. In the near surface space, the building density affects the sun shading conditions, shadow distributions, and ventilation conditions [11,17,37]. According to the actual measurement results of XCZ, the building density is divided into the following four levels: (1) $\leq 30 \%$, (2) 30-40\%, (3) 40-50\%, and (4) 50-60\%. Accordingly, the relationship between the urban form and thermal environment under different building density levels was investigated in this study (as shown in Figure 8).

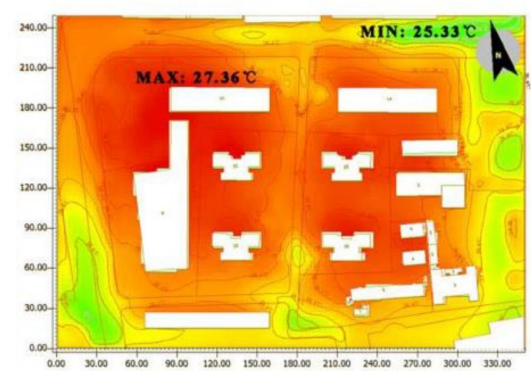

42 : Residential, Building density: $<30 \%$

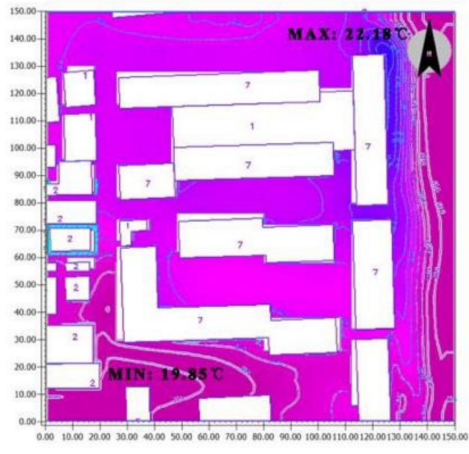

07 : Residential, Building density: $40 \%-50 \%$

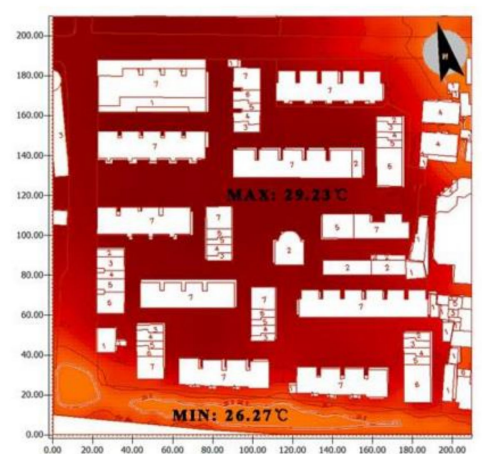

65 :Residential, Building density: $30 \%-40 \%$

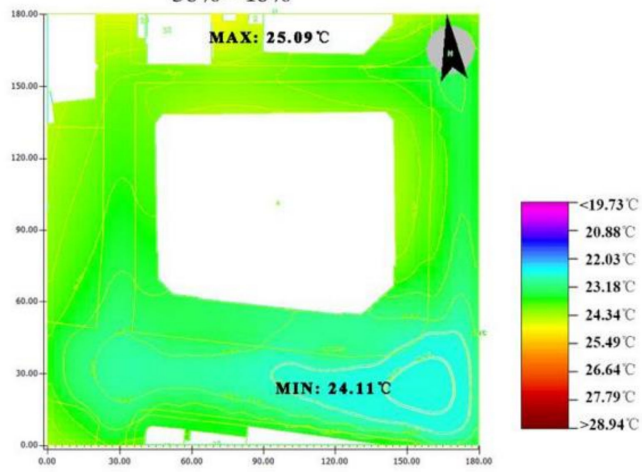

53 :Shopping mall, Building density: $>50 \%$

Figure 8. Building density versus thermal environment in near surface space.

Under the influence of building shadows and open space, the temperature inside street blocks is lower than that in ambient areas. When the building density is greater than $50 \%$, such as Plot 53 in Figure 8, a large architectural form is usually produced. However, because the air flow in the shadow of the building is blocked by the building itself, the air temperature in the shadow of the building is higher than that in the open space.

With the increasing of building density, the building interval decreases gradually. However, the temperature inside street blocks does not necessarily tend to increase or decrease with increasing building density. Evidently, a high building density reduces the temperature inside street blocks, but there is no direct correlation between the specific temperature and building density. However, an increase in building density reduces the ventilation and heat dissipation inside street blocks, causing perceived discomfort to humans. 


\subsection{Average Building Height Versus Thermal Environment in Near Surface Space of XZC}

The average building height is equal to the sum of the heights of all buildings divided by the total number of buildings, which is an important index for measuring the vertical urban form of street blocks. The variation in average building height affects the sunshine and shadows inside street blocks, causing changes in the wind environment and near urban surface temperature [22].

In accordance with the Code for Design of Civil Buildings in China, building height is classified into four types as follows: (1) high-rise (at least 18 stories); (2) medium and high-rise (8 to 17 stories); (3) multi-stories (4 to 7 stories); and (4) low-rise (1 to 3 stories) [38]. Accordingly, the urban form was investigated under different building height levels and thermal environments (shown in Figure 9).

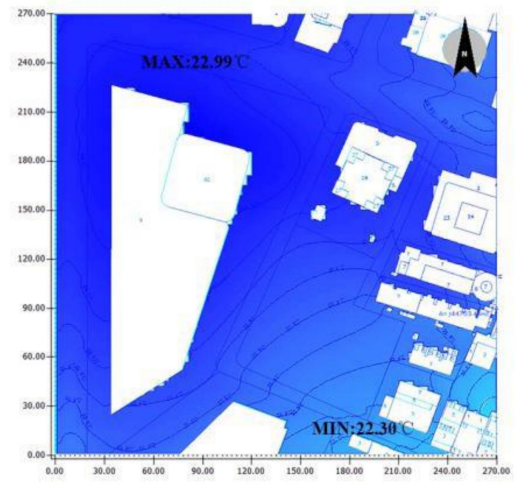

40 : Shopping mall, Average building height: high-rise

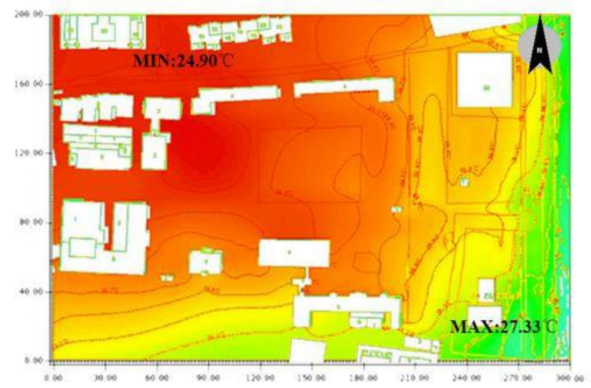

35 : Residential, Average building height: multistory

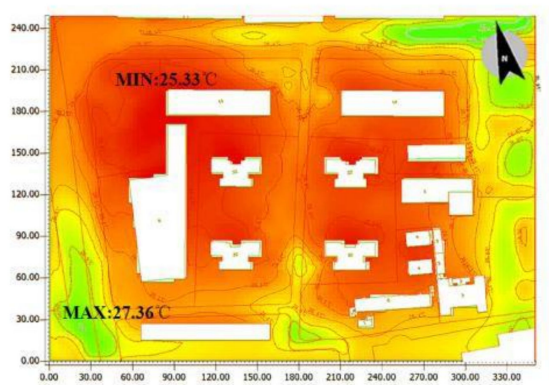

42 :Residential, Average building height: medium-high rise

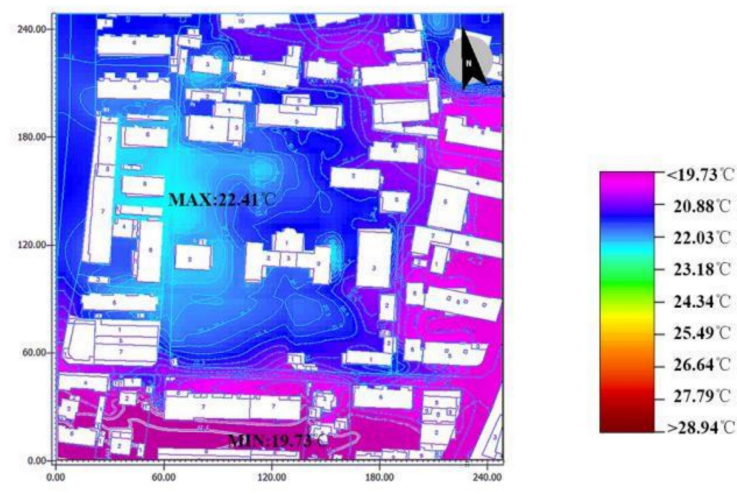

22 :Residential, Average building height: low-rise

Figure 9. Average building height versus thermal environment in near surface space.

Variation in building height does not have obvious trend of temperature distributions. However, the low-temperature area shadowed by buildings increases with increasing average building height. In particular, high-rise buildings affect the thermal environment of the surrounding areas significantly. On the one hand, high-rise buildings can produce large shadow ranges. On the other hand, the difference between the heights of high-rise buildings and the surrounding buildings causes the high-altitude airflows to move to the near surface space, optimizing the thermal environment of the near surface space. Therefore, the minimum temperature of street blocks is usually concentrated around high-rise buildings.

\subsection{Degree of Openness Versus Thermal Environment in Near Surface Space of XZC}

The degree of openness is an index used to represent the degree of closing or opening of the external space of street blocks. This index affects the mobility of air and is of great significance to the urban 
microclimate (e.g., thermal comfort) [39]. Within the near surface spatial range, the degree of openness has the following two meanings: (1) the degree of opening to space and (2) the degree of opening to surrounding areas (usually referred to as the degree of enclosure) [40]. A high degree of opening to the space mitigates the heat island effect and reduces the air temperature effectively [15]. The degree of enclosure is equal to the ratio of the length of the architectural interface along the outer border of a street block to the perimeter of the street block. It affects the ventilation effect of the street block [41] and is also an important influencing factor of the thermal environment inside the street block. Therefore, the relationship between the degree of enclosure and thermal environment was addressed in this study.

According to the calculation results for the degree of enclosure of $\mathrm{XCZ}$, four typical street blocks were selected for comparative analysis (as shown in Figure 10). The comparative analysis reveals that with increasing degree of enclosure in the near surface space, there are gradual increases in both the temperature inside the street blocks and temperature difference between inside and outside the street blocks. The upward trend is obviously reversed in the street block with the highest degree of enclosure, i.e., both the temperature inside this block and the temperature difference between the inside and outside is the lowest. Hence, it is difficult to determine the direct correlation between the degree of enclosure and the thermal environments of street blocks. It was merely found that the temperature variation is relatively drastic on both sides of an enclosed building but is relatively smooth in unenclosed and open areas. Evidently, enclosed buildings can obstruct the thermal radiation from surrounding roads into the interior of the blocks.

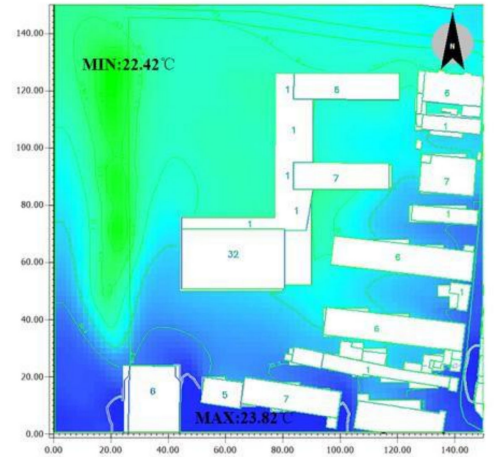

14 : Residential, Degree of enclosure: 0.34

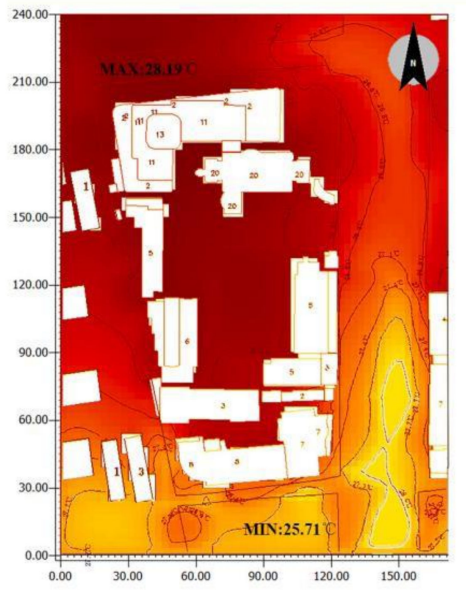

10 : Financial business, degree of enclosure: 0.59

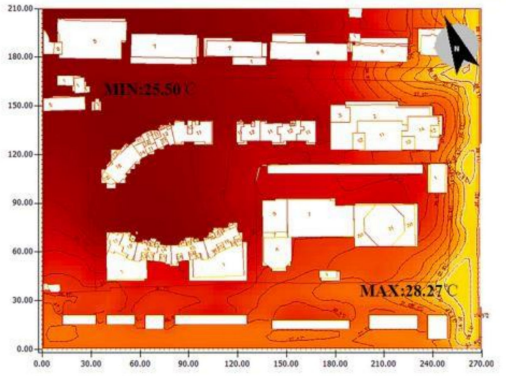

60 :Residential, Degree of enclosure:

0.44

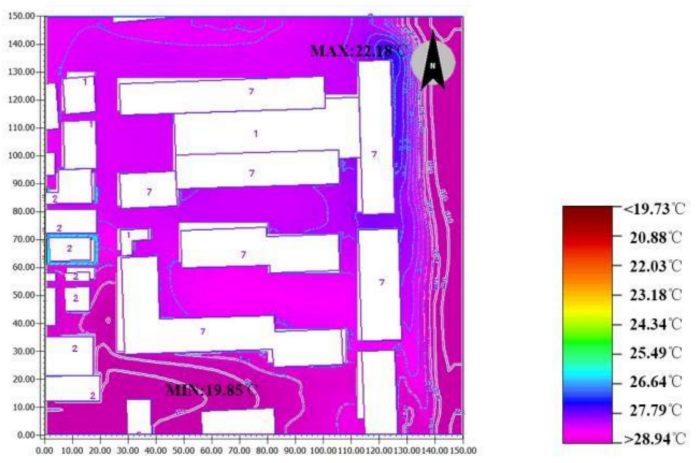

07 :Residential, degree of enclosure: 0.87

Figure 10. Degree of enclosure versus thermal environment in near surface space. 


\section{Optimization Strategy for Street Block Morphology and Extended Discussion}

\subsection{Measurement of Thermal Environments}

The thermal environments of urban near surface spaces have remarkable effects on human outdoor activities and are affected by complex and diverse factors, including motor vehicles, air conditioner external units, reflex of glass curtain walls, thermal radiation of the hard ground and outer walls of buildings, and building shadows. In traditional studies on thermal environments based on actual satellite remote sensing imaging, the thermal environment of the urban canopy layer has actually been studied [25-29], and it has not been possible to determine the thermal environments in the near surface space accurately. However, actual measurement of near surface thermal environments is a very complex problem, in which the selections of the locations and heights of the measurement points are the main issues.

For studies of thermal environments on a large spatial scale, actual measurement of the thermal environment should reflect the actual thermal environment maximally and eliminate the effects of factors capable of reducing temperature (e.g., architectural shadows). The intent is to simulate thermal environments under extreme adverse conditions, highlighting any contradictions and indicating any problems. Consequently, it is advisable to select road intersections or open hard ground spaces for actual measurement. These areas are always exposed to sunshine and are not shadowed by trees and buildings, thus, representing extreme adverse thermal conditions maximally. Moreover, the heads and five sensory organs of humans are very sensitive to thermal environments, and the sense of comfort under a particular thermal environment is based on personal feeling. Preferably, the height at which thermal environments are measured should be $1.5 \mathrm{~m}$, which basically corresponds to the height of the human head with an average stature.

\subsection{Balancing Function of Near Surface Urban Form}

As mentioned above in Section 3.2, in high-density built-up areas, building shadows can reduce the air temperature effectively [22,42]. Therefore, a greater building height and density (or a smaller building interval) are beneficial for reducing the air temperature inside street blocks. However, greater building height and density reduce the degree of openness, slow down ventilation and heat dissipation, and increase air humidity, thus, producing a sense of stuffiness. Hence, it is advisable to seek a balance between the building density and degree of openness. The intent is to optimize the thermal environment while ensuring the combined effects of architectural (building) shadows and urban ventilation. According to this study, the overall thermal environment of a street block is optimal when the building density is between $40 \%$ and $50 \%$ and the average building height is between 8 and 17 stories. The Design Guide to Sustainable Buildings [43], which is in effect in Hong Kong, expressly stipulates the degrees of ventilation of buildings with various heights, with the core purpose of promoting heat convection in the near surface space and enabling the optimization of thermal environments.

However, it should be noted that the spatial morphologies of street blocks are determined by their use functions. Large department stores with similar urban form indices are obviously different from residential communities in terms of urban form; this difference is directly associated with the supply and usage modes of specific functions [44]. While people seek a balance between urban form elements, it is also necessary to consider the spatial requirements of architectural functions. Specifically, it is not advisable to merely use thermal environment optimization as the starting point; otherwise, inefficient urban form will result in a waste of resources. Hence, the urban form is a critical node of conversion and enables humans to attain a balance between functional needs and the thermal environment, i.e., it enables humans to optimize thermal environments based on the satisfaction of functional needs (as shown in Figure 11). 


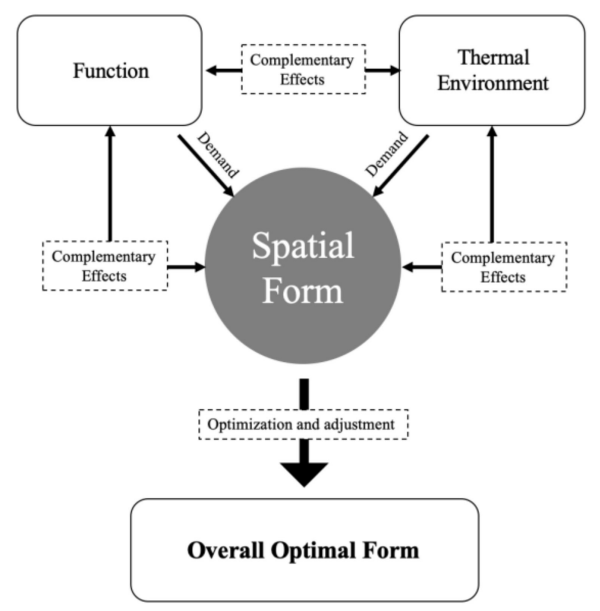

Figure 11. Action mechanism of urban form.

The aforementioned content only qualitative discusses the relationship between spatial morphology and the optimal thermal environment, further quantitative associations for thermal environment optimization should be carried out in the future research.

\subsection{Urban Form Strategy for Mitigating the Heat Island Effect}

In the actual built environment, there are many different types of spatial form under the same spatial form index. Therefore, through the classification of urban spatial functions, this paper adjusts the overall layout and morphological structure of different spatial functions to optimize the thermal environment. Each architectural function has relatively stable urban form. In high-density built-up areas, particularly urban centers, architectural functions can be classified as commercial, financial and business, and residential. Usually, commercial buildings are integrated and large buildings, financial and business buildings are densely arranged point-type or plate-type high-rise buildings, and residential buildings are plate-type buildings arranged in rows (in Asian countries, particularly in China, residential buildings are oriented north and south in most regions, to ensure adequate sunshine; thus, residential buildings are typically arranged in rows).

Residential areas have certain internal and open spaces and are mainly faced with the following problems: (1) In low-rise residential areas with row-by-row layouts, the building intervals are very small and (2) because of ground-floor shops along streets, the degree of enclosure is very high. Therefore, residential areas should be oriented to follow the summer prevailing wind direction to improve the ventilation between buildings arranged in rows. In addition, completely closed architectural interfaces should be avoided as much as possible; at the junctures of residential buildings, continuous enclosure interfaces should be opened properly, to promote air motion between inside and outside street blocks (as shown in Figure 12).
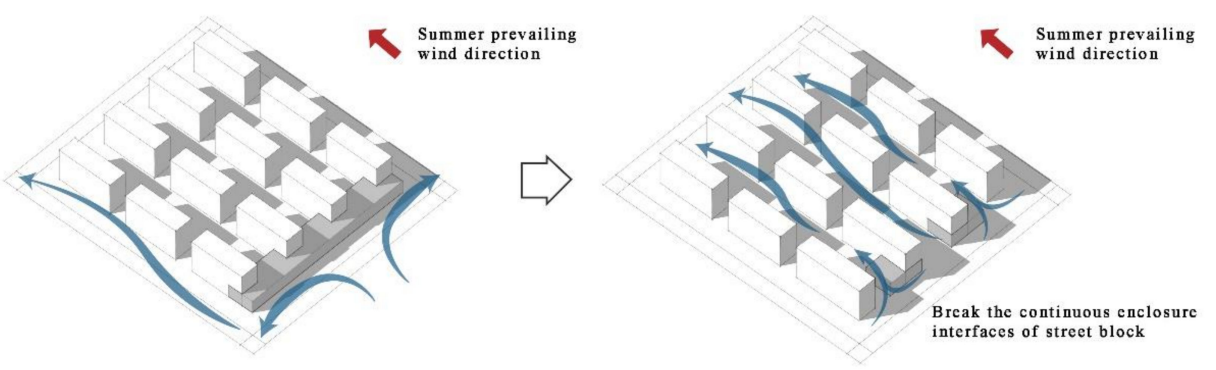

Figure 12. Urban form strategy for residential areas. 
Large commercial buildings severely obstruct the ventilation of the near surface space. Due to this characteristic, along with the heat dissipation of devices (e.g., air conditioners) and surrounding hard ground, the surrounding thermal environment is degraded. To optimize the surrounding thermal environment, it is advisable to expand the semi-outdoor space. Specifically, the following measures can be taken: (1) A large commercial building can be split into multiple functional partitions or (2) the roof of the atrium can be raised and the enclosures of surrounding roofs can be removed to form a few ventilation corridors that pass throughout the building and promote air circulation between horizontal and vertical spaces (as shown in Figure 13).

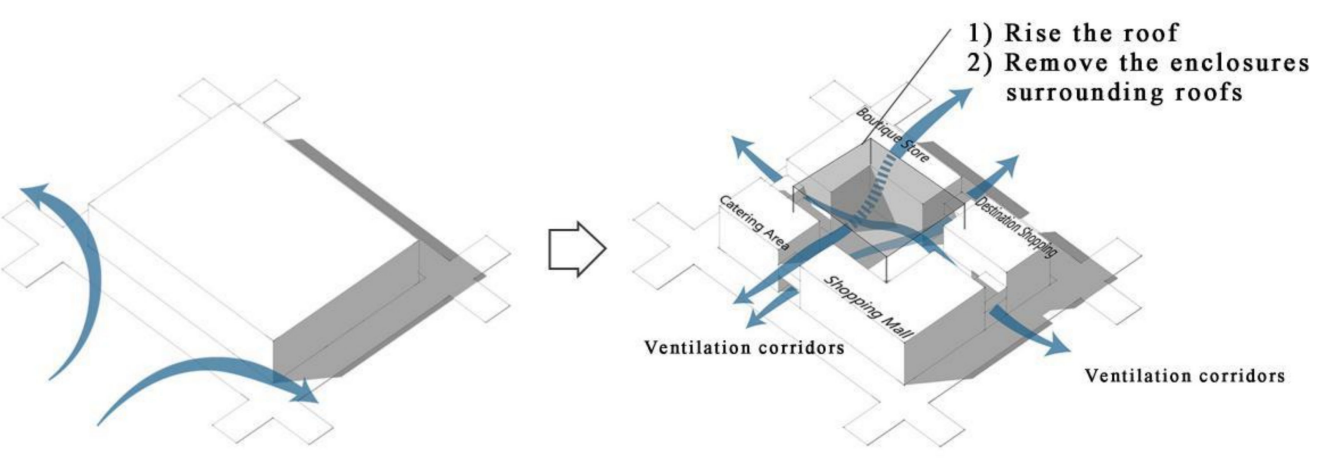

Figure 13. Urban form strategy for commercial areas.

Financial and business buildings are typically high-rise or super high-rise buildings and are usually arranged in two modes as follows: (1) scattered arrangements of multiple buildings or (2) integrated arrangements with large commercial buildings. If the buildings are arranged in a scattered pattern, it is necessary to note the relationship between the building layout and summer prevailing wind direction; specifically, the building layout should not hinder wind from blowing into the building cluster. If they are integrated with large commercial buildings, the morphology strategy for commercial buildings can be used for reference; specifically, they can be arranged in terms of functional modules.

In high-density built-up areas, air motion can be guided by taking full advantage of the air pressure difference arising from the variation in building height. Specifically, buildings with varying heights can be arranged in a ladder-like manner along the summer prevailing wind direction, guiding high-altitude wind to the near surface spaces between rows of buildings and promoting air circulation in the near surface space in high-density built-up areas [12]. The ultimate purpose is to optimize the thermal environments in high-density built-up regions (as shown in Figure 14).

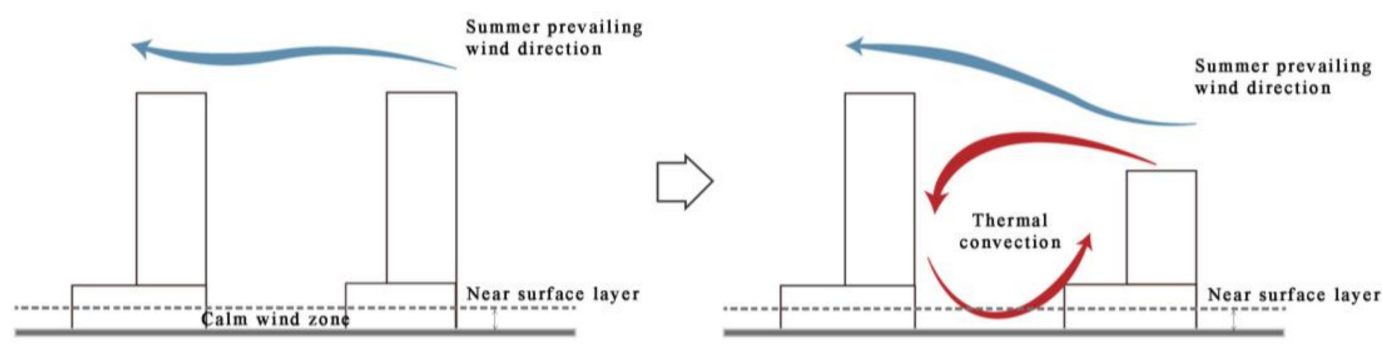

Figure 14. Urban form strategy for urban planning.

In high-density built-up areas, except for the study on urban thermal environments near the surface, the extended investigation of urban thermal environmental effects on indoor thermal comfort [45] should also be conducted, which is of great importance for human health and building energy efficiency [46], considering boundary conditions of solar radiation used for simulations [47,48]. The urban thermal environments are very complex, the evaluation indices of outdoor thermal comfort considering urban 
form should be also conducted, which can be more useful for urban design from the perspectives of thermal safety and health [49]. These can be future studies.

\section{Conclusions}

The study results showed that the urban form (e.g., building density, average building height, and degree of openness) could affect the thermal environments of street blocks. According to the analysis of XCZ in Nanjing, the specific street block morphology is closely related to the thermal environment, and the thermal environment varies with the street block morphology. Even in high-density built-up areas, the street block morphology can be improved to optimize the thermal environment and mitigate the heat island effect. The key issue lies in the degree to which the street block morphology can promote air circulation and heat dissipation.

In an actual urban space, the sizes, heights, and layouts of buildings are diverse, and the consequent urban form is highly complex and varied. Therefore, a single index (e.g., building density, average building height, or degree of openness) is not sufficient to measure the direct relationship between the urban form and thermal environment. It can merely be concluded that high density reduces the air temperature inside street blocks. The shadows of high-rise buildings and their guiding effects on high-altitude airflows are beneficial for reducing the temperature of ambient near surface air. Building enclosures effectively obstruct the radiation from high temperatures of road into street blocks. However, it cannot be proven that the building density, average building height, and degree of enclosure have direct effects on thermal environments.

Urban form and specific building functions affect one another, so there is an indirect relationship between building functions and thermal environments, which is regulated through urban form. Hence, it is asserted that in high-density built-up areas, the urban form can be improved to optimize the overall effects of the building functions and thermal environment. Furthermore, function-specific urban form optimization strategies are proposed to optimize thermal environments according to specific functional needs.

Author Contributions: J.Y. contributed to the conception of the study and as the main writer of the manuscript; B.S. contributed significantly to analysis and manuscript preparation, especially in urban form analysis; G.X. performed the site investigation and data analyses; Q.X. performed the site investigation and drawing design; S.-J.C. contributed to the general structure design of the manuscript, the analysis of thermal environment results and discussions, as well as correction and revision of the manuscript during the whole process. All authors have read and agreed to the published version of the manuscript.

Funding: This research was funded by the National Key R\&D Program of China "Digital Simulation and Evaluation Model for Reconstruction of Town and Village Settlements Space" (grant no. 2018YFD1100300).

Conflicts of Interest: The authors declare no conflict of interest.

\section{References}

1. De Oliveira, J.V.; Cohen, J.C.P.; Pimentel, M.; Tourinho, H.L.Z.; Lôbo, M.A.; Sodré, G.; Abdala, A. Urban climate and environmental perception about climate change in Belém, Pará, Brazil. Urban. Clim. 2020, 31, 100579. [CrossRef]

2. Maheshwari, B.; Pinto, U.; Akbar, S.; Fahey, P. Is urbanisation also the culprit of climate change?-Evidence from Australian cities. Urban. Clim. 2020, 31, 100581. [CrossRef]

3. Luo, X.; Yu, C.W.; Zhou, D.; Gu, Z. Challenges and adaptation to urban climate change in China: A viewpoint of urban climate and urban planning. Indoor Built Environ. 2019, 28, 1157-1161. [CrossRef]

4. Di, X.; Ruishan, C. Comparison of urban heat island and urban reflection in Nanjing City of China. Sustain. Cities Soc. 2017, 31, 26-36. [CrossRef]

5. Xian, G.; Crane, M. An analysis of urban thermal characteristics andassociated land cover in Tampa Bay and Las Vegas using Landsat satellite data. Remote Sens. Environ. 2006, 104, 147-156. [CrossRef]

6. Hugo, G. Future demographic change and its interactions with migration and climate change. Glob. Environ. Change 2011, 215, 521-533. [CrossRef] 
7. Salata, F.; Golasi, I.; Proietti, R.; de Lieto Vollaro, A. Implications of climate and outdoor thermal comfort on tourism. The case of Italy. Int. J. Biometeorol. 2017, 61, 2229-2244. [CrossRef]

8. Rangwala, L.; Pai, M. Planning for heat risk in vulnerable communities in Surat city. In Climate Change Planning, Proceedings of the 54th ISOCARP Congress, Bodo, Norway, 1-5 October 2018; International Society of City and Regional Planners: Hague, The Netherlands; pp. 140-160.

9. Bardhan, R.; Kurisu, K.; Hanaki, K. Does compact urban forms relate to good quality of life in high density cities of India? Case of Kolkata. Cities 2015, 48, 55-65. [CrossRef]

10. Habitzreuter, L.; Smith, S.T.; Keeling, T. Modelling the overheating risk in an uniform high-rise building design with a consideration of urban context and heatwaves. Indoor Built Environ. 2019. [CrossRef]

11. Chen, X.L.; Zhao, H.M.; Li, P.X.; Yin, Z.Y. Remote sensing image-based analysis of the relationship between urban heat island and land use/cover changes. Remote Sens. Environ. 2006, 104, 133-146. [CrossRef]

12. Yin, C.; Yuan, M.; Lu, Y.; Huang, Y.; Liu, Y. Effects of urban form on the urban heat island effect based on spatial regression model. Sci. Total Environ. 2018, 634, 696-704. [CrossRef] [PubMed]

13. Xing, Y.; Jones, P. In-situ monitoring of energetic and hydrological performance of a semi-intensive green roof and a white roof during a heatwave event in the UK. Indoor Built Environ. 2019. [CrossRef]

14. Xiao, X.D.; Dong, L.; Yan, H.; Yang, N.; Xiong, Y. The influence of the spatial characteristics of urban green space on the urban heat island effect in Suzhou Industrial Park. Sustain. Cities Soc. 2018, 40, 428-439. [CrossRef]

15. Yang, J.; Shi, Y.; Yu, C.; Cao, S.-J. Challenges of using mobile phone signalling data to estimate urban population density: Towards smart cities and sustainable urban development. Indoor Built Environ. 2019, 147-150. [CrossRef]

16. Xie, Y.; Liu, J.; Huang, T.; Li, J.; Niu, J.; Mak, C.M.; Lee, T.C. Outdoor thermal sensation and logistic regression analysis of comfort range of meteorological parameters in Hong Kong. Build. Environ. 2019, 155, 175-186. [CrossRef]

17. He, S.; Zhang, Y.W.; Gu, Z.L.; Su, J. Local climate zone classification with different source data in Xi'an, China. Indoor Built Environ. 2019, 28, 1190-1199. [CrossRef]

18. Yang, J.; Shi, B.; Shi, Y.; Marvin, S.; Zheng, Y.; Xia, G. Air pollution dispersal in high density urban areas: Research on the triadic relation of wind, air pollution, and urban form. Sustain. Cities Soc. 2020, 54, 101941. [CrossRef]

19. Chokhachian, A.; Perini, K.; Giulini, S.; Auer, T. Urban performance and density: Generative study on interdependencies of urban form and environmental measures. Sustain. Cities Soc. 2020, 53, 101952. [CrossRef]

20. Chun, B.; Guldmann, J.M. Impact of greening on the urban heat island: Seasonal variations and mitigation strategies. Comput. Environ. Urban. Syst. 2018, 71, 165-176. [CrossRef]

21. Chen, Y.C.; Yao, C.K.; Honjo, T.; Lin, T.P. The application of a high-density street-level air temperature observation network (HiSAN): Dynamic variation characteristics of urban heat island in Tainan, Taiwan. Sci. Total Environ. 2018, 626, 555-566. [CrossRef]

22. Giridharan, R.; Lau, S.S.Y.; Ganesan, S.; Givoni, B. Urban design factors influencing heat island intensity in high-rise high-density environments of Hong Kong. Build. Environ. 2007, 42, 3669-3684. [CrossRef]

23. Van Hove, L.W.A.; Jacobs, C.M.J.; Heusinkveld, B.G.; Elbers, J.A.; Van Driel, B.L.; Holtslag, A.A.M. Temporal and spatial variability of urban heat island and thermal comfort within the Rotterdam agglomeration. Build. Environ. 2015, 83, 91-103. [CrossRef]

24. Oliveira, V. Urban Morphology: An Introduction to the Study of the Physical Form of Cities; Springer: Berlin/Heidelberg, Germany, 2016.

25. Wang, W.; Liang, S.; Meyers, T. Validating MODIS land surface temperature products using long-term nighttime ground measurements. Remote Sens. Environ. 2008, 112, 623-635. [CrossRef]

26. Yang, J.; Shi, B.; Zheng, Y.; Shi, Y.; Xia, G. Urban Form and Air Pollution Disperse: Key Index and Mitigation Strategies. Sustain. Cities Soc. 2019, 101955. [CrossRef]

27. Yang, G.; Pu, R.; Zhao, C.; Huang, W.; Wang, J. Estimation of subpixel land surface temperature using an endmember index based technique: A case examination on ASTER and MODIS temperature products over a heterogeneous area. Remote Sens. Environ. 2011, 115, 1202-1219. [CrossRef]

28. Kong, L.; Lau, K.K.L.; Yuan, C.; Chen, Y.; Xu, Y.; Ren, C.; Ng, E. Regulation of outdoor thermal comfort by trees in Hong Kong. Sustain. Cities Soc. 2017, 31, 12-25. [CrossRef] 
29. He, B.J.; Zhao, Z.Q.; Shen, L.D.; Wang, H.B.; Li, L.G. An approach to examining performances of cool/hot sources in mitigating/enhancing land surface temperature under different temperature backgrounds based on Landsat 8 image. Sustain. Cities Soc. 2019, 44, 416-427. [CrossRef]

30. Yuan, F.; Bauer, M.E. Comparison of impervious surface area and normalized difference vegetation index as indicators of surface urban heat island effects in Landsat imagery. Remote Sens. Environ. 2007, 106, 375-386. [CrossRef]

31. Condon, P.M.; Cavens, D.; Miller, N. Urban Planning Tools for Climate Change Mitigation; Lincoln Institute of Land Policy: Cambridge, MA, USA, 2009.

32. Stone, B.; Hess, J.J.; Frumkin, H. Urban form and extreme heat events: Are sprawling cities more vulnerable to climate change than compact cities? Environ. Health Perspect. 2010, 118, 1425-1428. [CrossRef]

33. Shi, B.; Yang, J. Scale, distribution, and pattern of mixed land use in central districts: A case study of Nanjing, China. Habitat Int. 2015, 46, 166-177. [CrossRef]

34. Chen, Y.; Wu, J.; Yu, K.; Wang, D. Evaluating the impact of the building density and height on the block surface temperature. Build. Environ. 2020, 168, 106493. [CrossRef]

35. Wang, Y.; Zhou, D.; Wang, Y.; Fang, Y.; Yuan, Y.; Lv, L. Comparative study of urban residential design and microclimate characteristics based on ENVI-met simulation. Indoor Built Environ. 2019, 28, 1200-1216. [CrossRef]

36. Xu, Y.; Ren, C.; Ma, P.; Ho, J.; Wang, W.; Lau, K.L.; Lin, H.; Ng, E. Urban morphology detection and computation for urban climate research. Landsc. Urban Plan. 2017, 167, 212-224. [CrossRef]

37. Guo, A.; Yang, J.; Xiao, X.; Xia, J.; Jin, C.; Li, X. Influences of urban spatial form on urban heat island effects at the community level in China. Sustain. Cities Soc. 2020, 53, 101972. [CrossRef]

38. China Institute of Building Standard Design and Research (CIBSDR). Code for Design of Civil Buildings; China Architecture \& Building Press: Beijing, China, 2019.

39. Doherty, M.; Nakanishi, H.; Bai, X.; Meyers, J. Relationships between form, morphology, density and energy in urban environments. GEA Backgr. Pap. 2009, 28, 1-28.

40. Lai, A.; Maing, M.; Ng, E. Observational studies of mean radiant temperature across different outdoor spaces under shaded conditions in densely built environment. Build. Environ. 2017, 114, 397-409. [CrossRef]

41. Arnfield, A.J.; Grimmond, C.S.B. An urban canyon energy budget model and its application to urban storage heat flux modeling. Energy Build. 1998, 27, 61-68. [CrossRef]

42. Vallati, A.; de Lieto Vollaro, A.; Golasi, I.; Barchiesi, E.; Caranese, C. On the impact of urban micro climate on the energy consumption of buildings. Energy Procedia 2015, 82, 506-511. [CrossRef]

43. Building Department of the Hong Kong Government. Practice Note for Authorized Persons, Registered Structural Engineers and Registered Geotechnical Engineers PNAP APP-152: Sustainable Building Design Guidelines; (Chinese Version); BD: Hong Kong, China, 2011.

44. Cheng, C.K.; Chan, J.C. Impacts of land use changes and synoptic forcing on the seasonal climate over the Pearl River Delta of China. Atmos. Environ. 2012, 60, 25-36. [CrossRef]

45. Deng, Y.; Feng, Z.; Fang, J.; Cao, S.J. Impact of ventilation rates on indoor thermal comfort and energy efficiency of ground-source heat pump system. Sustain. Cities Soc. 2018, 37, 154-163. [CrossRef]

46. Cao, S.J.; Deng, H.Y. Investigation of temperature regulation effects on indoor thermal comfort, air quality, and energy savings toward green residential buildings. Sci. Technol. Built Environ. 2019, 25, 309-321. [CrossRef]

47. Ren, C.; Cao, S.J. Development and application of linear ventilation and temperature models for indoor environmental prediction and HVAC systems control. Sustain. Cities Soc. 2019, 51, 101673. [CrossRef]

48. Chen, H.; Feng, Z.; Cao, S.J. Quantitative investigations on setting parameters of air conditioning (air-supply speed and temperature) in ventilated cooling rooms. Indoor Built Environ. 2019. [CrossRef]

49. Fang, Z.; Feng, X.; Liu, J.; Lin, Z.; Mak, C.M.; Niu, J.; Tse, K.T.; Xu, X. Investigation into the differences among several outdoor thermal comfort indices against field survey in subtropics. Sustain. Cities Soc. 2019, 44, 676-690. [CrossRef]

(C) 2020 by the authors. Licensee MDPI, Basel, Switzerland. This article is an open access article distributed under the terms and conditions of the Creative Commons Attribution (CC BY) license (http://creativecommons.org/licenses/by/4.0/). 